\title{
Influence of Grain Size on Sediment Transport Rates with Emphasis on the Total Longshore Rate
}

US Army Corps of Engineers $s_{\odot}$

by David B. King, Jr.

PURPOSE: The calculation of longshore sediment transport (LST) rates is a key component of most coastal engineering studies. While the LST process is conceptually simple, in practice the development of reliable rates is made difficult by problems associated with collecting accurate field data, by limitations to model predictions, and by substantial variations of the rates in time and space.

This Coastal and Hydraulic Engineering Technical Note (CHETN) summarizes the state of understanding of the influence of grain size on surf zone sediment transport and is a companion to Smith et al. (2004). This CHETN discusses details of bed-load and suspended load transport, and the classical bed-load regime is shown to encompass two distinct modes of transport. Four LST models with varying levels of complexity are discussed to show how they incorporate the physics of grain size variation and its effect on the transport rate. In addition, a relationship between the $K$ coefficient in the CERC formula (Coastal Engineering Manual (2002), Section III-2-3-a) and grain size is presented. Finally, some inconsistencies between theory and data are discussed in the context of the interrelationship between grain size and beach slope.

The final conclusion is repeated here. In general, an increase in the median grain size will decrease LST rates in the surf zone. If a simple exponential relationship between transport rate and grain size $(D)$ is needed (Equation 7: LST rate $\propto D^{n}$ ), the most appropriate value for the exponent $n$ should be of the order of -1 , as seen from Equation 23. However, this tech note argues that this is clearly a simplistic view of surf zone sediment dynamics. A more realistic (though still highly simplified) approach would be that, for fine grain sediments ( $D_{50}$ on the order of 0.15 to $0.30 \mathrm{~mm}$ ), suspended load transport should dominate and $n$ should be somewhere within the range of -0.5 to -3.0 . For coarse sands ( $D_{50}$ around $1.0 \mathrm{~mm}$ ), sheetflow bed-load transport should dominate (Figure 6 ), and the transport rate should be nearly independent of grain size $(n=0)$. For large gravel and shingle $\left(D_{50}\right.$ $>20 \mathrm{~mm}$ ), the dominant transport should be in the IM (Initial Motion) bed-load regime, with $n$ within the range of -0.5 to -2.0 . To state this another way, the exponent $n$ in Equation 7 is itself a function of grain size.

BACKGROUND: Though most researchers recognize the median grain size as a parameter of first order importance in its effects on the magnitude of sediment transport, its variation is not as easily studied as the variation of many of the other primary parameters. In the field, it is easy to obtain data for a range of values for wave heights and periods, for instance, as these vary constantly in time. However, the grain size on a beach typically shows no (or insignificant) variations in time. Similar problems can occur in the laboratory. Changing the wave height or period in a laboratory study is usually as simple as reprogramming a wave paddle. However, usually, changing the grain size in a large model is infrequently done because of the large cost in both time and money. 
Consequently, the effects of grain size on sediment transport rates is not as well understood as for some other parameters. Grain size has occasionally been incorporated into models to make expressions dimensionally correct, rather than based upon theory or data.

Relationship of Grain Size to Fall Velocity and Shear Stress. The fall velocity is the terminal velocity reached by a sediment particle as it falls through an infinite, quiescent fluid, where the fluid drag retarding the particle is equal to the downward gravitational pull. Many sediment transport relationships (particularly suspended load relationships) contain a fall velocity parameter $\left(w_{s}\right)$ with or without a separate grain-size parameter ( $D$ or $D_{50}$, the median grain diameter). Fall velocity increases with grain diameter. For silts and clays, $w_{s}$ varies as $D^{2}$ and for gravels it varies as $D^{1 / 2}$. For sand-size particles, $w_{s}$ falls in a transition region where it varies as the grain size to a power between $1 / 2$ and 2 (Coastal Engineering Manual 2002, Section III-1). For convenience, this relationship can be crudely approximated as a variation to the first power for sand-size particles, but to obtain accurate values, a formula such as those of Hallermeier (1981) or Ahrens (2000) should be used.

An important parameter in sediment transport is the shear stress $(\tau)$, which is the tangential force per unit area that a moving fluid exerts on the sediment bed, which causes transport. In a wave dominated environment, it is generally related to the horizontal fluid velocity just above the top of the boundary layer $(u)$ by the expression:

$$
\tau=1 / 2 f_{w} \rho u^{2}
$$

where $\rho$ is the fluid density, and $f_{w}$ is the friction factor. The stress on the bed is strongly affected by the nature of the flow within the boundary layer. The boundary layer flow can be laminar or turbulent; it is affected by the bed roughness and the presence of bed forms such as ripples; and it is substantially different in steady versus oscillatory flow. Generally, an attempt is made to represent these effects as variations in the $f_{w}$ term. In oscillatory flow, the $f_{w}$ term is usually inversely related to the dimensionless term $\left(a / k_{s}\right)$, where $a$ is the orbital excursion amplitude and $k_{s}$ is the bed roughness. For flat beds with sand or larger grain sizes, $k_{s}$ is directly related to the grain size. Several equations have been proposed for this relationship (e.g., Jonsson 1966; Swart 1974; Kamphuis 1975; Nielsen 1979). For the purposes of this discussion, the important result is that, for sand- and gravel-sized particles, an increase in the sediment grain size will cause a small increase in the shear stress on the bed, which will lead directly to a slightly greater sediment transport rate for the same free-stream flow conditions. While this effect is important, it can be easily masked by other greater influences that the size of the sediment has on the transport rate, as discussed in the following paragraphs.

Minimum and Maximum Beach Sediment Sizes. The lower grain-size limit for the material composing most beaches is in the 0.10 - to $0.15-\mathrm{mm}$ range. This value is largely controlled by ambient near-bottom turbulence levels. There are two primary sources of turbulence in the surf zone: breaking wave turbulence and turbulence generated within the wave or wave/current bottom boundary layer. The turbulence generated by breaking waves is substantially larger, but is generated at the top of the water column and its effect on the bed is highly episodic on both wave and storm time scales. Sediment picked up by breaking wave suspension events will at least occasionally have enough time to settle back to the bed before the next event. However, small grains (slits and clays, with low fall velocities) are mobilized by the turbulence generated in the bottom boundary layer and 
kept in suspension throughout a half wave cycle. The same thing occurs on next half cycle, and the material never settles to the bed. Instead, the material is kept in suspension and slowly diffuses or is transported into quiescent waters elsewhere, either offshore or into back bays and estuaries. This process is analogous to that which supports wash loads in rivers. Beaches with grain sizes smaller than about $0.10 \mathrm{~mm}$ are usually only found near large river deltas (such as many sections of the coast of Louisiana), where the system is overwhelmed by the presence of fine sediments and coarser material is unavailable.

Few beaches are composed of material whose median grain size is larger than $100-300 \mathrm{~mm}$. The maximum size of beach materials is governed by the rate at which large materials can be delivered to a beach by rivers, eroding bluffs, etc., compared with the rate at which these materials weather (ablate) once they are on the beach. The weathering of cobble-sized materials can be quite rapid in a geological sense. In comparison, the fine quartz sands $(0.15$ to $0.3 \mathrm{~mm})$ that compose most beaches have so little mass that they are almost totally resistant to further weathering. For additional discussion, see Coastal Engineering Manual (2002), Section III-1.

SEDIMENT TRANSPORT REGIMES: The theory leading to the development of the CERC formula was based upon the concept that waves deliver a certain amount of energy to the surf zone, and that a constant proportion of this energy is available to mobilize and transport sediment (Bagnold 1963; Inman and Bagnold 1963; Bagnold 1966). Though remarkable, this development had been found to have limitations. As waves break and release energy across the surf zone, the proportion of this energy used to transport sediment is not constant, but varies substantially through surf zone parameter space. The understanding that surf zone sediment transport is not a simple process that can be described by a simple one-term equation has led to the development of more sophisticated equations employing the concept of sediment transport regimes.

Most of the LST models in use today are either one-term models that calculate the total load or they have two terms that partition the LST into bed-load and suspended load components. However, there are at least five nearshore sediment regimes that can realistically dominate the transport under certain conditions: two bed-load regimes, the suspended load regime, the ripple regime, and the swash regime. A complete nearshore transport relationship would include components for the calculation of transport in each of these regimes, or include an analysis that indicated which were important for a given set of input parameters and then only calculate those.

The bed-load and suspended load regimes are discussed in detail in the following paragraphs with emphasis on how the transport is affected by grain size. Ripple transport is generally considered as being the same as suspended load transport over flat beds, except that $k_{s}$ is dominated by ripple height over the grain diameter. However, significant differences are recognized, including suspension occurring primarily or exclusively at the ripple crest, sediment trapping vortices of standard size forming in the lee of each ripple and dissipating each half cycle, and transport processes that differ in space along the length of the ripple. Ripple transport also is visually quite distinct from suspended load transport on flat beds. To the extent that this complex process is understood and can be parameterized, the variation of longshore transport rate with grain size in this regime is thought to be similar to that in the suspended load regime. In both, the transport strongly decreases with increasing grain size. 
The swash zone is defined as the area between the minimum and maximum wave uprush for a given tide stage. In the swash zone, transport occurs through the mechanisms of bed-load and suspended load. However, several factors make this region distinct. The shallow depths generally allow the boundary layer to grow to the water surface, making aspects of the transport more similar to steady flow in rivers than to typical unsteady transport by waves. Though generally a large percentage of the wave energy has dissipated before reaching the swash, the small depths in this region mean that the dissipation at the water surface occurs close to the bed. This has the potential to elevate near-bed turbulence levels, compared to the levels further offshore in the surf zone. The relatively high transport rates frequently seen in the swash may be a result of this fact. Flow into and out of the bed (percolation) is substantially more pronounced in the swash than in deeper parts of the surf zone. This both changes the hydrodynamics of uprush and downrush, and it changes the shear stress at the bed, leading directly to changes in mobilization and transport of the sediment. While these effects are understood qualitatively, how they alter the relationship between grain size and transport rate needs substantial further work.

Bed-load Transport Regimes. Bed-load is defined as that portion of the moving sediment that is supported by intergranular contact, either continuously through rolling or sliding motion, or intermittently through saltation (Bagnold 1956). This is distinct from suspended load, which is that portion of the moving sediment that is supported by the turbulent fluid drag. These distinctions are useful for model development but make precise measurements of the two quantities difficult, as both processes occur at the same elevation above the bed, or may be partially supporting the same grain at any given moment.

Many bed-load to total load sediment transport models incorporate a threshold of motion term to deal with low transport rates. A more physically realistic approach is to consider bed-load transport as occurring in two regimes, an IM bed-load regime and a sheetflow bed-load regime. In sheetflow, there is a dense layer of sediment many grain diameters thick in motion just above the stationary (flat) bed. (In this discussion, sheetflow will refer only to bed-load transport, and will not include material, which may or may not be carried in suspension above it.) This layer rises and collapses with each half cycle of fluid motion. For less intense transport (decreasing $\tau$ ), this moving sediment layer decreases in both thickness and velocity. This concept of a moving sheet of material works well until the thickness of the layer decreases to the order of a grain diameter. Below this value, the transport layer thickness cannot continue to smoothly decrease. Instead, transport occurs by some of the grains in the surface layer moving substantial distances while others are remaining stationary. This is the IM bed-load regime.

Though there are no obvious visual differences in these regimes (such as distinguishes ripple transport from suspended load, for instance), there are marked differences in the behavior of the sediment. Several researchers have measured bed-load transport in the laboratory using a variety of facilities and measurement techniques. Figure 1 shows half cycle transport ratios when beds of different sized sediments were subjected to the same flow fields. This figure shows the amount of bed-load transport for the smaller material divided by the amount for the larger. The $\mathrm{x}$-axis is the Shield's parameter, $\theta$ :

$$
\theta=\frac{\tau_{m}}{\left(\rho_{s}-\rho\right) g D}
$$




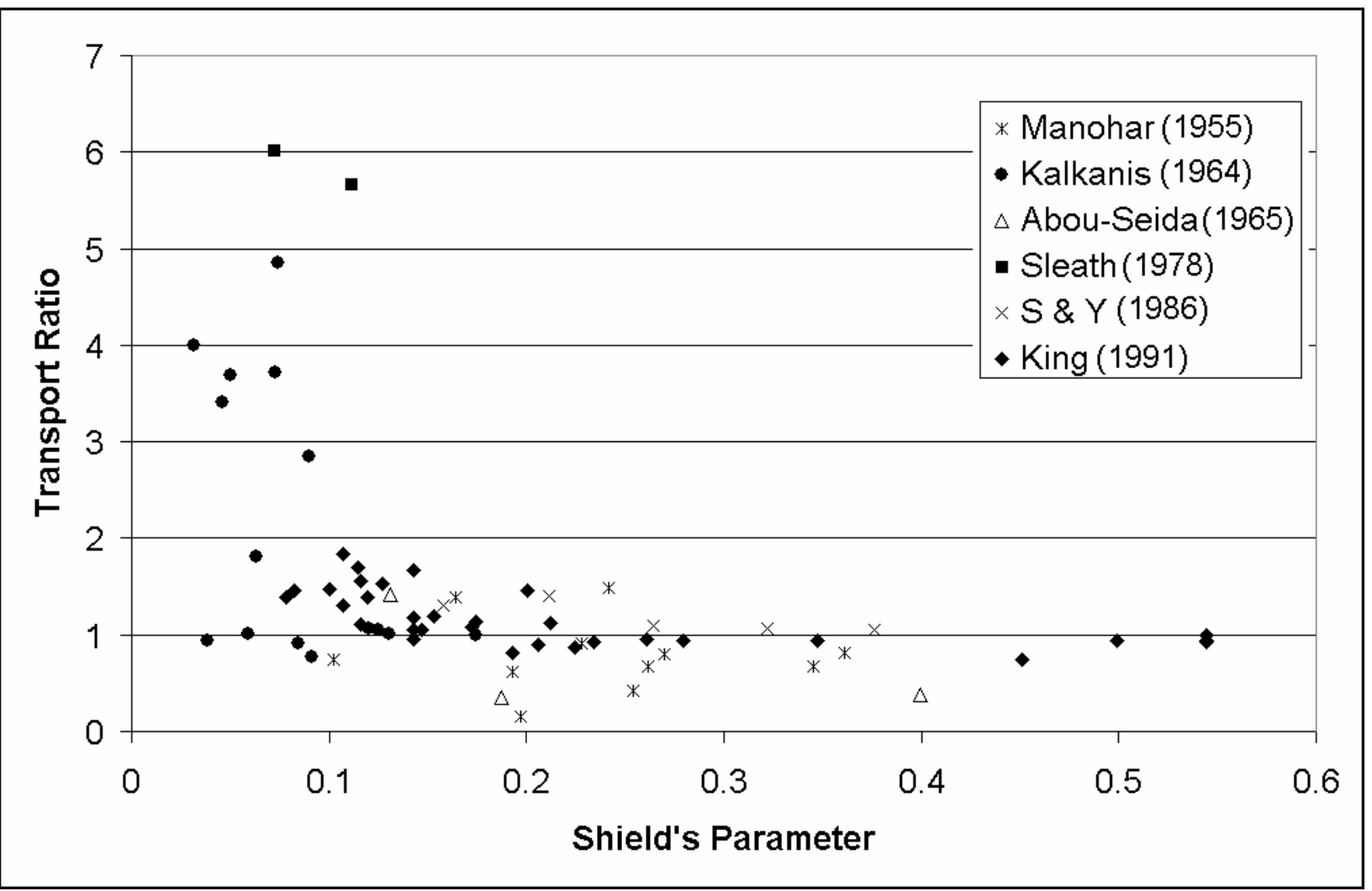

Figure 1. Laboratory data for ratio of sediment transport occurring over a half wave cycle for a smaller grain size divided by a larger grain size, when both are subjected to same flow field (modified from King 1991)

where $\tau_{m}$ is the maximum orbital shear stress equal to $1 / 2 f_{w} \rho u_{m}{ }^{2}, \rho_{\mathrm{s}}$ is the sediment density, and $u_{m}$ is the maximum orbital water velocity above the bottom boundary layer. The shear stress was calculated as suggested in Nielsen (1992) and Soulsby (1997) with the bed roughness $k_{s}=2.5 D$, and $f_{w}$ was calculated using the formula of Swart (1974). The D's in the Shield's parameter were calculated using the larger grain diameter for each pair of sediments. Plotted ratios are limited to those where both values were measured by the same researchers using the same apparatus and measurement technique, to reduce the impact of experimental error, and where the flow fields for both tests (excursion amplitudes, periods, and maximum velocities) varied by less than 3 percent. Grain sizes for the data shown in Figure 1 are listed in Table 1. Data also were excluded if the suspension parameter, $b$, was less than 1.5 for either grain size, indicating that a substantial fraction of the transport was occurring as suspension. The dimensionless suspension parameter is:

$$
b=\frac{w_{s}}{\kappa u_{*}}
$$

where $w_{s}$ is the sediment fall velocity, calculated using Ahrens (2000), $\kappa$ is von Karman's constant $=0.40$, and $u *$ is the friction velocity $=\sqrt{\tau_{m} / \rho}$. 
ERDC/CHL CHETN-II-48

November 2005

\section{Table 1}

Grain Sizes for Figures 1 and 2

\begin{tabular}{||l|l|l|l||}
\hline \hline Author & \# of Ratios & $\begin{array}{l}\text { Numerator Grain Size } \\
\mathbf{m m}\end{array}$ & $\begin{array}{l}\text { Denominator Grain Size } \\
\mathbf{m m}\end{array}$ \\
\hline \hline Manohar (1955) & 11 & 0.28 & 1.006 \\
\hline Kalkanis (1964) & 15 & $1.68,2.18$ & $2.18,2.82$ \\
\hline Abou-Seida (1965) & 2 & $0.30,1.21$ & $1.21,2.61$ \\
\hline Sleath (1978) & 2 & 1.89 & 4.24 \\
\hline Sawamoto and Yamashita (1986) & 5 & 0.7 & 1.6 \\
\hline King (1991) & 32 & 0.44 & 1.1 \\
\hline
\end{tabular}

Figure 1 shows a distinct break in the trend of the data occurring near $\theta \approx 0.2$. For larger values of the Shield's parameter, the transport is nearly independent of grain size. Below $\theta \approx 0.2$, there is a strong decrease in transport rate with increasing grain size. In a series of papers, Bagnold (1954, $1956,1963,1966)$ has shown that the shear stress, $\tau_{m}$, necessary to transport a given immersed weight of sediment, $P$, is governed by Coulomb's law of sliding friction:

$$
\frac{\tau_{m}}{P}=\tan \phi
$$

where $\phi$ is the angle of repose. The immersed weight of sediment per unit area one-grain layer thick is:

$$
P=\left(\rho_{s}-\rho\right) g D(1-p)
$$

where $p$ is the porosity of the sediment. In terms of the Shield's parameter, a one-grain diameter thick layer corresponds to:

$$
\theta=(1-p) \tan \phi
$$

Using $p=0.4$ and tan $\phi=0.58$, Equation 6 yields a value of $\theta=0.35$ for a transport layer one grain diameter thick. Sawamoto and Yamashita (1987, their figure 13a) present a graphical relationship between the depth of the moving sediment layer and the Shields parameter. Their data show that a moving sediment thickness of a one grain layer occurs near $\theta \approx 0.2$.

Figure 1 indicates that in the sheetflow bed-load regime, which occurs for $\theta \geq 0.2$, the transport rate is largely independent of grain size. In this regime, the shear stress at the bed is able to mobilize a large mass of sediment per unit surface area, and it makes little difference whether that mass is composed of many small grains or fewer larger grains. If the relationship between transport rate and grain size can be expressed as:

$$
\text { transport rate } \propto D^{n}
$$


then, for the ratios in Figure 1, $n$ can be found as:

$$
n=\frac{\log (\text { transport ratio })}{\log \left(D_{1} / D_{2}\right)}
$$

where $D_{1}$ is the smaller grain size and $D_{2}$ is the larger. Using his data, King (1991) found that in the sheetflow regime: $n \approx 0.08$, as shown in Figure 2, demonstrating the small influence of grain size on transport rate.

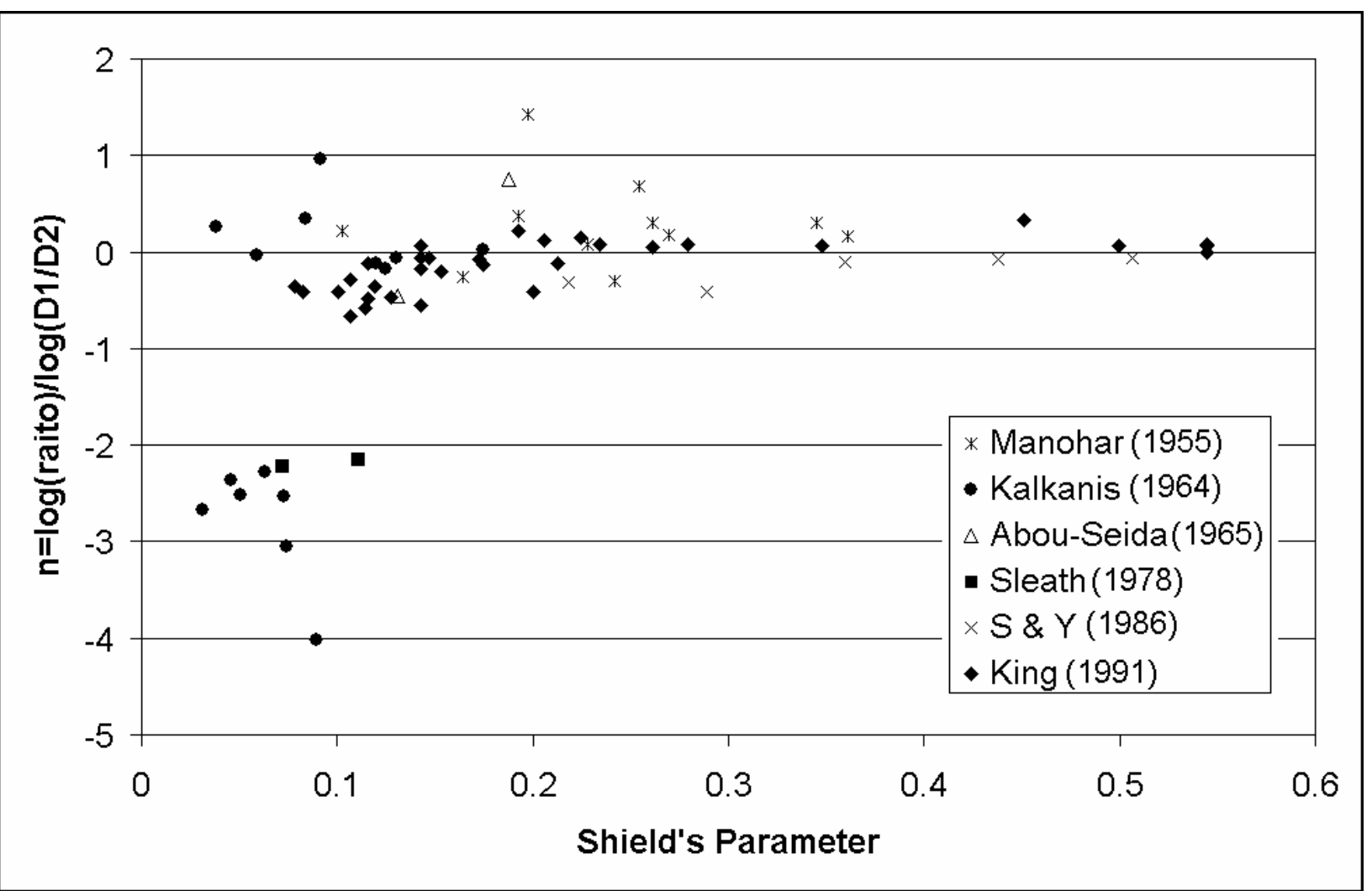

Figure 2. Calculation of exponent $n$ in Equation 8 for transport ratios shown in Figure 1

In the IM bed-load regime, whether a grain in the surface layer moves or not is a function of the flow intensity $(\tau)$, of the chance of impact from other saltating grains, and of how a grain is sitting and resting against its neighbors. At sand sizes and larger, large grains are less easily dislodged and transported than small, making transport a function of grain size.

Sawamoto and Yamashita $(1986,1987)$ developed a relationship for sediment transport in the IM bed-load regime. Ignoring the effect of grain size on the friction factor $\left(f_{w}\right)$, their relationship indicates:

transport rate $\propto D^{-2}$ 
The description of the Sleath (1978) experiments indicate that both grain sizes were clearly within the IM regime, as he photographed and measured the motion of individual particles. As seen in Figure 2, his limited data set also indicates that for this regime, $n$ should be near -2 . There is substantial scatter in the data of Kalkanis (1964) and, unfortunately, his methodology is not well described.

The threshold of motion is included within the IM regime at a critical Shields parameter value of the order of $\theta_{\mathrm{c}} \approx 0.04$ to 0.06 . Thus, the threshold of grain motion should be a function of grain diameter. Sleath (1984) (section 6.6.1) lists many common threshold of motion formulas and grain size is a parameter included in most of these equations. However, most of these formulas indicate that the appropriate grain size exponent in Equation 9 should be between 0 and -1. Clearly, more data would be useful in exploring the behavior of transport in this regime and its relationship to grain size.

In the laboratory, if experiments are conducted using periodic waves to transport sand at rates a little above threshold, ripples form on the bed. However, these ripples take time to form (many wave periods, depending upon the flow intensity). Prior to their formation, transport is in the IM bed-load regime, but after they form, it is in the ripple regime. The situation is somewhat more complicated with irregular waves, in that large waves will occasionally wipe out the ripples, causing the process to start over. So transport will alternate between these regimes; however, it will usually be in the ripple regime. As shear stresses increase, ripples go through a progression of modifications until they are wiped out at a Shield's parameter value of the order of $\theta \approx 0.8$. This is well within the sheetflow bed-load regime. Thus, the presence of ripples has tended to mask the existence of two bed-load regimes. Studies of the IM bed-load regime must generally be done before ripples develop or at large-grain diameters, for ripples do not tend to form for grain sizes above $D \approx 0.8 \mathrm{~mm}$.

From shallow-water linear wave theory, the maximum horizontal velocity $\left(u_{m}\right)$ is:

$$
u_{m}=\frac{1}{2} H \sqrt{g / d}
$$

where $H$ is wave height and $d$ is water depth. Using this relationship plus Equation 2, the boundary equation, $\theta \approx 0.2$, between the two bed-load regimes is found to be equivalent to:

$$
\frac{H_{b}}{D} \approx \frac{1.6\left(\frac{\rho_{s}}{\rho}-\rho\right)}{\gamma f_{w}}
$$

where $\gamma$ is the breaking criteria (equal to $H_{b} / d$ ). Inserting the approximate values $\gamma=0.78, f_{w} \approx 0.015$, and $\rho_{\mathrm{s}}=2.65$ (quartz sand density), yields the equivalent boundary relationship in a breaking wave: $H_{b} / D \approx 230$. For the fine sands common on most beaches where $D$ is on the order of $0.2 \mathrm{~mm}$, breaking wave heights are almost always greater than a few centimeters; so this value is almost always exceeded, and bed-load occurs in the sheetflow bed-load regime as a dense layer of moving material, many grain diameters thick. However, on coarse grain beaches (gravel or shingle) where $D$ 
is on the order of 0.01 to $0.1 \mathrm{~m}$, this $H_{b} / D$ value is rarely exceeded and bed-load occurs in the IM regime in which transport decreases as grain size increases.

Are Two Bed-load Regimes Necessary? As fine grain beaches are predominant worldwide, and, on these, the presence of ripples will generally render calculations of transport in the IM bedload regime unnecessary, it is appropriate to consider if the recognition of two bed-load regimes can be expected to lead to improved estimates of sediment transport rates. The impact is likely to be of significance in two ways. First, on coarse-grained (gravel and cobble) beaches, suspended load transport does not occur (the suspension parameter, Equation 3, is large), sheetflow bed-load transport does not occur because the waves are not energetic enough, and ripples do not generally form at grain sizes above $D \approx 0.8 \mathrm{~mm}$. Therefore, by default, on these beaches IM bed-load transport can be expected to be the dominant transport mechanism. Secondly, the inclusion of two regimes will lead to improved equations for bed-load transport in the sheetflow regime. The description of sheetflow transport should be relatively simple. It is approximately independent of grain size and a threshold term does not need to be included, because threshold of motion occurs outside of this regime.

It is not mandatory that bed-load transport be divided into two regimes. A single appropriate equation could be devised that included the threshold of motion and the behavior described in Figure 1. However, the types of formulations commonly employed to include threshold effects have significant limitations (King and Seymour 1989). For example, Sleath (1978) proposed the following transport relationship:

$$
\frac{Q}{\omega D^{2}}=47\left(\theta-\theta_{c}\right)^{3 / 2}
$$

where $Q$ is the volume transport rate per unit width and $\omega$ is the wave frequency. In this equation, the threshold term, $\theta_{c}(\approx 0.05)$ substantially affects (depresses) the transport rate at Shield's parameter values well above $\theta \approx 0.2$. At $\theta=0.7$ the transport rate is only 90 percent of the value it would be if the threshold term were not included in the equation. Most transport equations that include a threshold term include it in a similar fashion.

The transport equation of Madsen and Grant (1976) does a much better job of limiting the effect of the threshold term to the region near threshold:

$$
\frac{Q}{w_{s} D}=C \theta^{3}
$$

where $C$ is a parameter related to the percentage of time in a wave cycle when the velocities are above threshold. The $C$ values are defined in a table in their paper. This parameter incorporates the threshold of motion because $C=0$ at $\theta=\theta_{c}$; it reaches its full value of $C=12.5$ at $\theta=4 \theta_{c} \approx 0.2$. However, this equation does not treat the grain size dependence correctly. If $f_{w}$ is assumed to be independent of $D$, and $w_{s} \propto D$, this equation implies that the transport is proportional to $D^{-1}$ for all values of the Shield's parameter. 
Suspended Load Transport Regime. For sediment suspension to occur, the vertical turbulence must be sufficient to counteract the fall velocity, $w_{s}$. See Nielsen (1992) for a detailed description of the process. The level of turbulence is a function of the maximum wave induced bottom shear stress, $\tau_{m}$, or, alternatively, the friction velocity, $u *$. This reasoning leads directly to the Rouse or suspension parameter, Equation 3, being important in the description of sediment suspension.

Many formulas have been proposed to describe suspended load sediment transport. Essentially all of these indicate that the rate decreases with grain size, or equivalently, with fall velocity, and most indicate that the transport rate is strongly inversely dependent on grain size. For a typical development, the suspended load sediment transport rate within a vertical column of unit area in the surf zone can be given as:

$$
Q(x, t)=\int_{0}^{d} c(x, z, t) \times u(x, z, t) d z
$$

where $c(x, z, t)$ is the sediment concentration and $u(x, z, t)$ is the sediment velocity, with both terms being functions of cross-shore $(x)$ and vertical $(z)$ position and time $(t)$.

To obtain the total longshore suspended load transport rate, $Q_{y, s}$, this equation can be integrated over a wave cycle and across the surf zone. In the gradient diffusion model, the settling of grains toward the bed at the fall velocity, $w_{s}$, is balanced by turbulent diffusion, given as:

$$
w_{s} C(z)=-\varepsilon \frac{d C}{d z}
$$

where $\varepsilon$ is the eddy diffusivity of sediment. For rippled beds, the eddy diffusivity can be assumed constant with height and the corresponding concentration profile is given as:

$$
C(z)=C_{0} e^{-z / l}
$$

where $C_{0}$ is the reference concentration and $l$ is the decay length scale.

Numerous equations have been proposed for the reference concentration, the decay length scale, and for the form of the concentration profile. Nielsen (1992) proposed that the reference concentration is proportional to the cube of the ripple Shield's parameter, and the decay length is a function of ripple geometry. This development leads to the suspended load transport rate being approximately equal to $D^{-3}$. Transport relationships developed for flat beds generally give similar results.

LONGSHORE SEDIMENT TRANSPORT MODELS: Four LST models are discussed later to show how they incorporate the physics of grain-size variation and its effect on the transport rate: the CERC formula, the Kamphuis model, the Bailard model, and the Madsen and Tajima model. The models selected are not intended to be inclusive, but merely representative of classes of models. The CERC equation, containing one term for the calculation of total load (combined bed-load and suspended load), is the simplest formula in general use. The Kamphuis formula is also a one-term, total load model, but explicitly includes the effects of wave period, beach slope, and grain size. The 
Bailard formula is representative of models that partition the transport into bed-load and suspended load transport. The Madsen and Tajima model is representative of the complex computer routines that model the hydrodynamics and sediment dynamics stepwise across the surf zone, and thus predict not only the total bed-load and suspended load LST, but also its cross-shore distribution.

CERC Formula. The most common method of calculating the total LST rate in use today is the CERC formula (Shore Protection Manual 1977, 1984; Coastal Engineering Manual 2002), which is given as:

$$
I=\frac{K}{16 \sqrt{\gamma_{b}}} \rho g^{\frac{3}{2}} H_{b}^{\frac{5}{2}} \sin \left(2 \alpha_{b}\right)
$$

where $I$ is the total immersed weight LST rate, $K$ is an empirical coefficient, $H_{b}$ is the breaking wave height, $\gamma_{b}$ is the breaker index (typically equal to 0.78 ), and $\alpha_{b}$ is wave angle at breaking. An equivalent expression is:

$$
Q=\frac{K}{16\left(\frac{\rho_{s}-\rho}{\rho}\right)(1-p)} \sqrt{\frac{g}{\gamma}} H_{b}^{\frac{5}{2}} \sin \left(2 \alpha_{b}\right)
$$

where $Q$ is the total bulk volume LST rate (volume of the grains plus voids).

This model, which is based on the assumption that the total longshore sediment transport rate is proportional to longshore energy flux, was developed from the pioneering work of Bagnold in the early 1960s and further developed by Komar and Inman (1970). For a detailed description of the development, see Dean and Dalrymple (2002).

The limitations of the CERC formula are well known. With adequate calibration, the CERC formula can estimate LST rates within \pm 50 percent. However, without calibration, the CERC formula only provides an accuracy of one to two orders-of-magnitude (Greer and Madsen 1978; Fowler et al. 1995; Wang et al. 1998). However, the CERC equation continues to be useful, primarily because of its simplicity and because of the failure of more sophisticated models to clearly demonstrate substantially superior accuracy relative to the effort required to employ them.

Variation of CERC $\boldsymbol{K}$ With Grain Size. The recommended value of the CERC $K$ coefficient depends upon whether the breaking wave height is specified in terms of the significant wave height or the root-mean-square wave height. See Galvin and Scheppe (1980) for a discussion of the relationship between these quantities. Following Schoonees and Theron (1994), in this technical note $K$ will be subscripted, where necessary, to reduce ambiguity. $K_{(s i g)}$ will refer to $K$ values associated with the significant wave height, and $K_{(r m s)}$ will refer to root-mean-square wave height $K$ values. Where necessary to convert between these quantities, the equation: $K_{(s i g)}=1 / 2 K_{(r m s)}$ is used. The Shore Protection Manual (1984) recommends a value of $K_{(s i g)}=0.39\left(K_{(r m s)}=0.78\right)$, which was based upon 41 measurements of LST rate. 
Several attempts have been made to modify the $K$ coefficient to improve the CERC formula and this has frequently involved relating $K$ to the grain size, as most investigators have concluded that the LST rate should decrease as grain size increases (Dean 1978; Walton and Chui 1979; Bruno et al. 1980; Dean et al. 1982; Dean 1989; Dean and Dalrymple 2002).

Komar (1988) examined most of the available field data, and questioned the validity of some. He concluded that existing data, most of which were for sand-size beaches, showed little relationship between $K$ and grain size. Theory and data showed a trend of decreasing $K$ with increasing grain size, but the data were too limited to establish a correlation. Komar stressed that $K$ should depend on sediment grain size, and the absence of such a trend in his analysis resulted from the imperfect quality of the data. For sand-sized grains, he recommended a $K_{(r m s)}=0.57$, based upon 70 data points. In comparison, Kraus et al. (1982) used 25 data points to recommend a value of $K_{(r m s)}=0.58$. Bodge and Kraus (1991) gave another extensive review of problems associated with use of the CERC equation.

Schoonees and Theron (1993) compiled and reviewed 35 data sets containing 273 measurements of bulk longshore transport rate. They devised a rating system and assessed the quality of the sets. Then Schoonees and Theron (1994) used portions of the data set to evaluate several version of the CERC formula. They also divided the data into those with grain sizes less than $1 \mathrm{~mm}$ and those with greater. For the fine-grained data set (206 points), they found a best fit $K_{(s i g)}=0.20$. If only the highest quality data sets were used (as per Schoonees and Theron 1993, 46 data points) they obtained a best fit $K_{(s i g)}=0.41$. However, the correlation was only slightly higher for the second set than the first $\left(R^{2}=\right.$ coefficient of determination $=0.77$ for second set versus 0.72 for the first $)$. For the data set with sediment larger than $1 \mathrm{~mm}$ (34 data points), they obtained $K_{(s i g)}=0.01$, but the correlation coefficient was only $R^{2}=0.11$.

It is generally accepted that there is a relationship between the CERC $K$ term and grain size. Formulas relating those two quantities have been proposed by Swart (1976), Bailard (1984), USAEWES (1985), Kamphuis et al. (1986) and del Valle et al. (1993).

Swart (1976) used a different form of the CERC relationship. Following Schoonees and Theron (1994), his relationship can be expressed as:

$$
K_{(r m s)}=1.15 \log _{10}\left(0.00146 / D_{50}\right)
$$

where the median grain diameter is in meters. The relationship is valid between $0.1 \mathrm{~mm}<D_{50}<1.0 \mathrm{~mm}$. He commented that, intuitively, he would have expected a steeper curve. The Bailard (1984) relationship is given below in the development of his model. USAEWES (1985) gives a relationship that relates $K$ to the fall velocity and also to the wave height. This expression, which was calibrated with the field data available at that time, is:

$$
K_{(s i g)}=0.1637 \log \left(\frac{g H_{b}}{w_{s}^{2}}\right)-0.0773
$$


Kamphuis et al. (1986) developed a relationship based upon dimensional analysis, which includes the wave height and breaker index, as well as the grain size. His expression is:

$$
K_{(s i g)}=0.022 \sqrt{\gamma * H_{b} / D}
$$

del Valle et al. (1993) developed an empirically based relationship for $K$, which shows decreasing values of $K$ with larger grain sizes. The equation was based on data presented by Komar (1988) and data obtained from their research along the Adra River Delta, Spain. The relationship is:

$$
K_{(r m s)}=1.4 e^{\left(-2.5 D_{50}\right)}
$$

where $D_{50}$ is expressed in millimeters. This relationship is strongly dependent on the relatively larger median sand grain sizes from the Adra River Delta $\left(D_{50}=0.44\right.$ to $\left.1.5 \mathrm{~mm}\right)$, and they cautioned against its use for grain sizes above $1.5 \mathrm{~mm}$.

Figure 3 shows data relating the CERC $K$ term to sediment grain size. It includes the field studies listed in Komar (1988), plus the gravel and shingle transport studies of Nicholls and Webber (1987), Chadwick (1989), and Nicholls and Wright (1991) from England, and Leidersdorf et al. (1988) from Alaska. Though there is a clear trend of decreasing transport with increasing grain size, there is also extensive scatter in the data, with more scatter for the larger grain sizes.

The trend in the data suggests a relationship of the form:

$$
K_{(s i g)}=\frac{0.1 \mathrm{~mm}}{D}
$$

However, due to the wide divergence of the data, this formula should only be used for initial estimates, and should not be substituted for site-specific field measurements. The formulas of Swart (1976) and del Valle et al. (1993) are also shown over the ranges for which the authors claim validity. For sand size materials, all three equations predict similar $K$ values. However, for larger gravels, their formulas predict a rapidly decreasing $K$, which is outside the scatter of the data, and thus, their formulas should only be employed within their stated data ranges.

Kamphuis Model. Kamphuis (1991) expanded upon his earlier work leading to Equation 20 and developed a relationship for estimating longshore sediment transport rates based upon dimensional analysis and calibrated this relationship using physical model experiments. The equation, which Kamphuis (2002) found to be applicable to both field and model data, is expressed as:

$$
Q_{u}=2.27 H_{s b}^{2} T_{p}^{1.5} m_{b}^{0.75} D_{50}^{-0.25} \sin ^{0.6}\left(2 \alpha_{b}\right)
$$

in which $Q_{u}$ is the transport rate of underwater mass $(\mathrm{kg} / \mathrm{sec}), T_{p}$ is the peak wave period $(\mathrm{sec}), m_{b}$ is the beach slope from the breaker line to the shoreline, and $D_{50}$ is the median grain size (mm). 


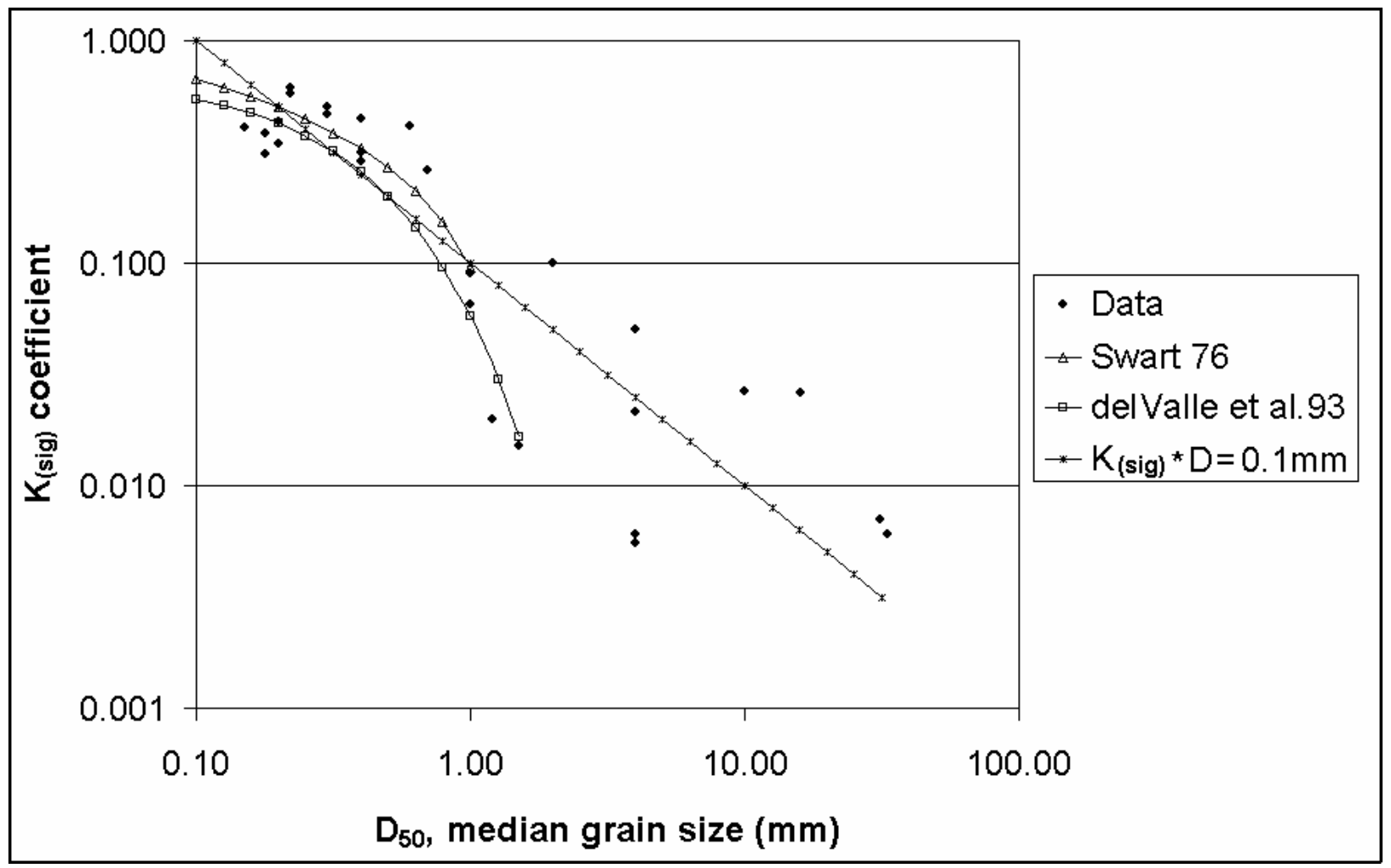

Figure 3. Relationship between CERC $K$ term and grain size

Kamphuis (2002) uses the same equation, but redefines the beach slope as the slope that causes breaking, i.e., the slope over one or two wavelengths offshore of the breaker line. Equation 24 is appealing because it includes the effects of wave period, which influences wave breaking (Galvin 1968), beach slope, and grain size. Numerous other researchers have developed formulas that relate the LST rate to a suite of parameters that include grain size. Some of these are van Hijum and Pilarczyk (1982); Brampton and Motyka (1984); Morfett (1988); Chadwick (1989); and Van Wellen et al. (2000).

Bailard Model. Bailard (1981) developed an energy based surf zone sediment transport model based upon Bagnold's $(1963,1966)$ steady flow models. His model had both bed-load and suspended load components. Both components were expressed in terms of various instantaneous velocity components, which limited its usefulness. Bailard (1984) made several simplifying assumptions and found that he could collapse both the bed-load and suspended load components to the form of the CERC equation if the $K$ term was of the form:

$$
K_{(r m s)}=0.05+2.6 \sin ^{2}\left(2 \alpha_{b}\right)+0.0096 m+0.007 \frac{u_{m b}}{w_{s}}
$$

where $w_{s}$ is the fall speed of the sediment, $m$ is the beach slope, and $u_{m b}$ is the maximum oscillatory velocity magnitude at breaking obtained from Equation 10. In Equation 25, the first three terms are contributions from the bed-load portion of his model, and the last is the suspended load portion. Also, the $m$ term is usually neglected because of its small size. 
Madsen and Tajima Model. Madsen and Tajima (Tajima 2004) developed a computer routine to model surf zone sediment transport. The code is in the form of two programs that run sequentially: a hydrodynamics model and a sediment transport model. The hydrodynamic model calculates the forcing functions needed to drive the sediment transport model at each point on the profile, and includes modules for nonlinear wave propagation, wave breaking, surface rollers, and nearshore currents. The sediment transport model calculates the transport at each profile point and includes bed-load and suspended load modules.

Model inputs include wave height, period, and direction, median sediment size or size distribution, beach profile, and various physical and model control parameters. The model contains no adjustable calibration coefficients such as the CERC $K$ coefficient. Model outputs include wave-average values for wave height, setup, and current across the profile, the cross-shore distribution of bed, suspended, and total load LST rate, along with bulk values for each, and vertical sediment distributions at user defined cross-shore locations.

An example of the suspended load and bed-load model predictions is shown in Figure 4. $Q$ is the bulk volume (sediment plus voids $(p=0.4)$ ) yearly LST rate that would occur for a constant breaking wave height with a period of $(T=8 \mathrm{sec})$ and breaking wave angle of $(\alpha=15 \mathrm{deg})$ on a grain-size-adjusted equilibrium beach profile. The suspended load transport shows a significant decrease in transport rate with increasing grain size, while the bed-load rate is largely grain size independent.

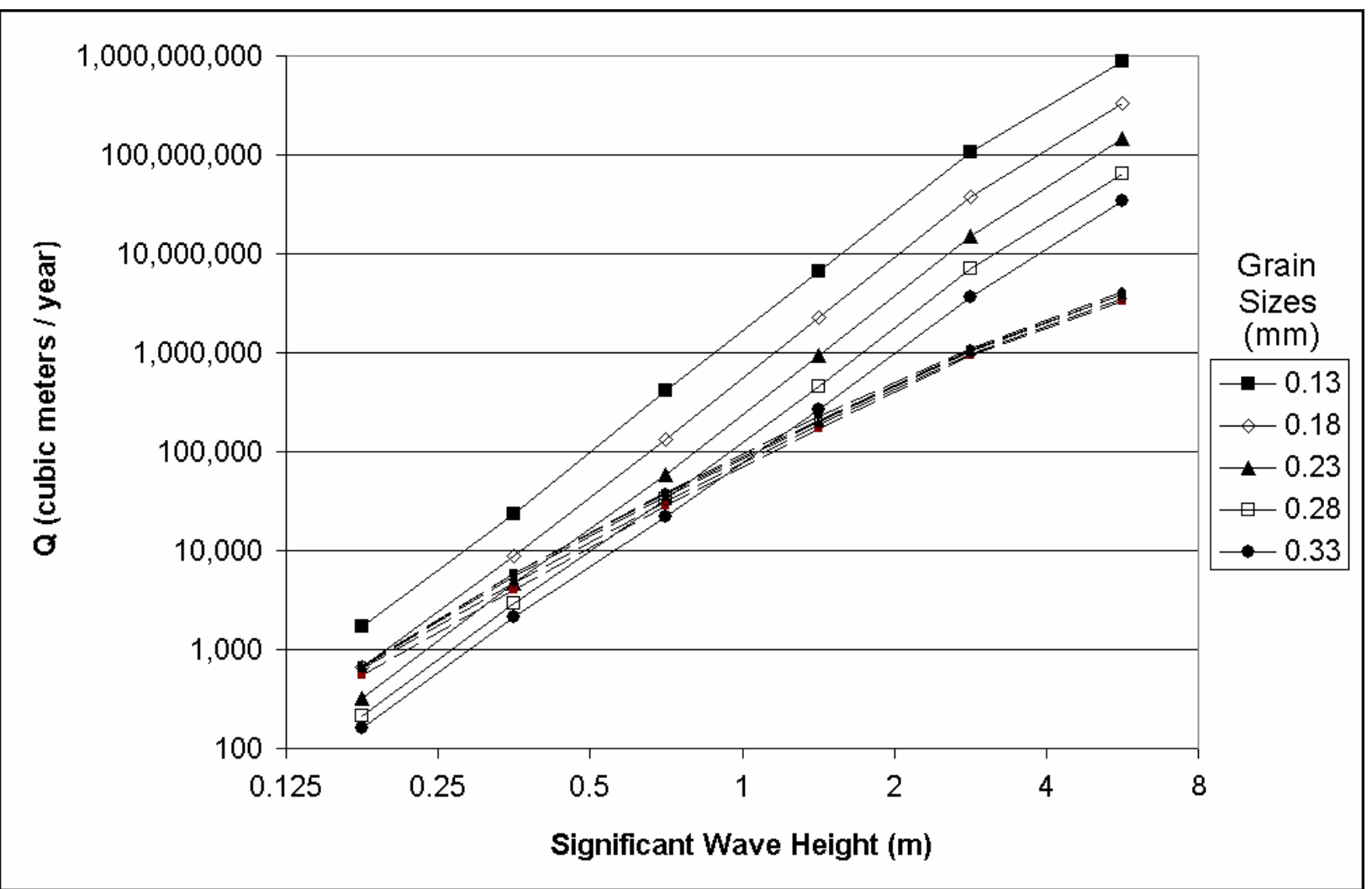

Figure 4. Madsen and Tajima model suspended load (solid lines) and bed-load (dashed lines) LST rate predictions 
MODEL LST PREDICTIONS OF EFFECTS OF GRAIN SIZE: To show how variations in grain size affect the model predictions, the four models previously described were run using two typical beach sediments with grain sizes $D=0.13$ and $0.33 \mathrm{~mm}$. The models used wave periods of $T=8 \mathrm{sec}$, breaker wave angles of $\alpha_{b}=15 \mathrm{deg}$, and equilibrium-shaped profiles for each grain size. The results for each model are shown in Figure 4 as ratios of the LST rate. The ratios plotted are the smaller grain size LST rate $(D=0.13 \mathrm{~mm})$ divided by the larger $(D=0.33 \mathrm{~mm})$ as a function of significant wave height.

It was previously shown (Equation 11 ) that the ratio $H_{b} / D$ is approximately equivalent to the Shield's parameter, $\theta$. As the grain sizes in Figure 5 are held constant, the horizontal axis on this figure is analogous to the horizontal axes in Figures 1 and 2. Both $\theta$ and $H_{b} / D$ can be thought of as ratios of the tangential force mobilizing the sediment to the gravitational force resisting the motion. In Figure 5, all bed-load transport should be considered to be in the sheetflow regime, because the boundary for the larger grain size should be at a wave height of approximately $7 \mathrm{~cm}$. (None of the models explicitly include a term representing IM bed-load transport.)

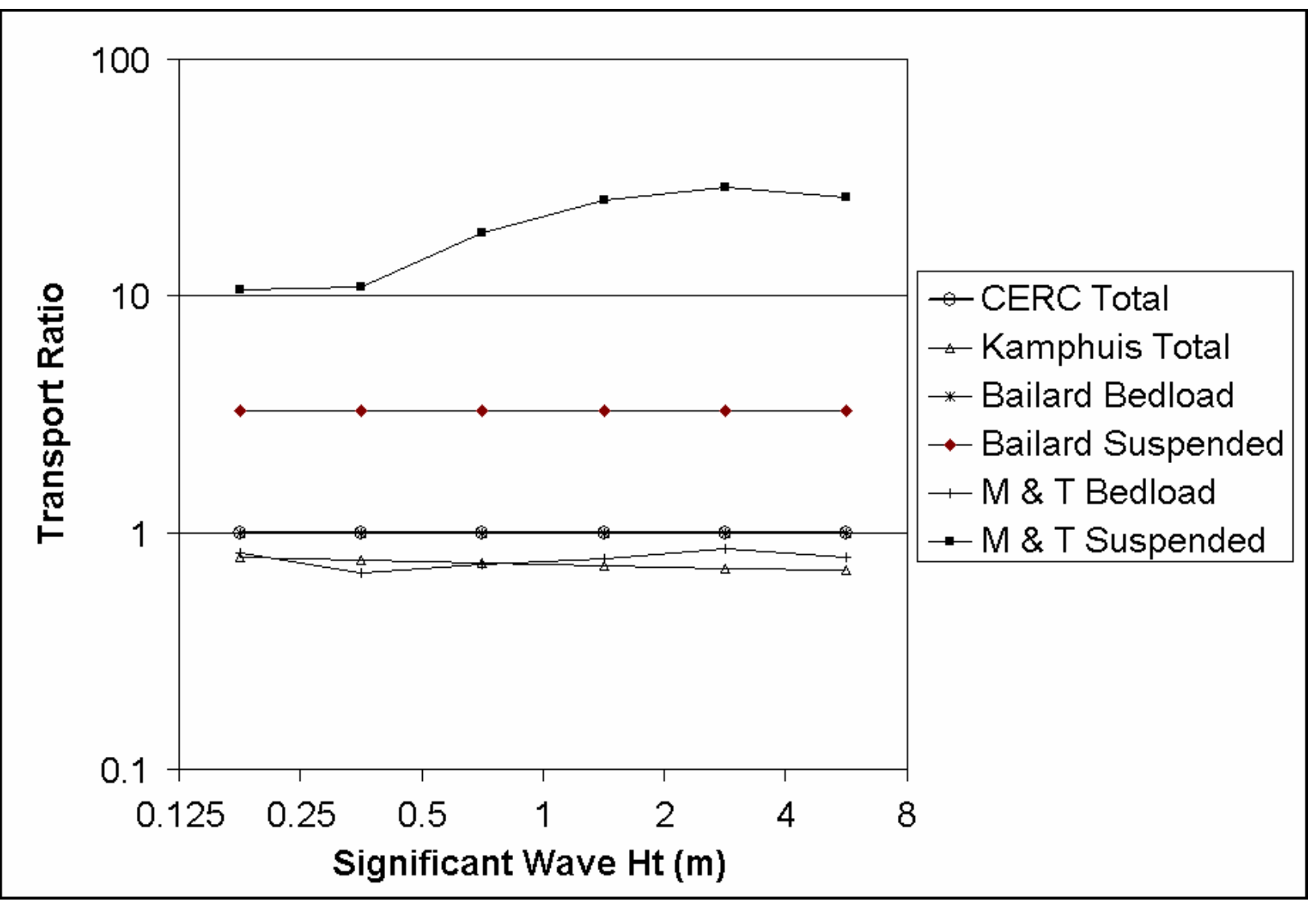

Figure 5. Comparison of model predictions for ratio of $0.13 \mathrm{~mm}$ grain size to $0.33 \mathrm{~mm}$ transport rate

The CERC formula and the Bailard bed-load formula have no grain size dependence, so for both, the ratio $=1$. The Kamphuis total load ratio and the Madsen and Tajima bed-load ratio are both slightly less than one. For the Madsen and Tajima model, this is due to the larger bed roughness for the larger grain size. The Kamphuis ratio is not constant because equilibrium beach slopes were used for 
each grain size, and the Kamphuis formula explicitly includes beach slope. If the same profile had been used for both Kamphuis runs, the transport ratio would be 1.26, implying greater transport for the smaller grain size. The ratio for the Bailard suspended load model is the inverse of the fall velocity ratio for the two grain sizes (=3.29). The Madsen and Tajima suspended load model includes a formulation of the type discussed in the section on the Suspended Load Regime above, and, as expected, shows significantly greater transport for the smaller grain size.

Table 2 shows the value of the exponent $n$ for each model using the simple assumption that transport is proportional to $D^{n}$ (Equation 7). These $n$ values were either taken directly from the model formulation or were calculated using Equation 8. In general, the table shows that bed-load transport is largely independent of grain size, while suspended load transport strongly decreases as grain size increases.

\begin{tabular}{||l|l||}
\hline \multicolumn{2}{|l||}{$\begin{array}{l}\text { Table } 2 \\
\text { Model Dependence on }\end{array}$} \\
\hline \hline Model & Transport $=\boldsymbol{D}^{n}$ \\
\hline \hline CERC Total Load & $D^{0}$ \\
\hline Kamphuis Total Load & $D^{-0.25}$ \\
\hline Bailard Bed-load & $D^{0}$ \\
\hline Bailard Suspended Load & $W_{s}^{-1}$ \\
\hline M \& T Bed-load & $D^{n}$ where $0.2<n<0.4$ \\
\hline M \& T Suspended Load & $D^{n}$ where $-3.6<n<2.5$ \\
\hline \hline
\end{tabular}

CERC FORMULA PARADOX: Figure 6 shows the ratio of suspended load transport to bed-load transport as a function of wave height and grain size as predicted by the Madsen and Tajima model (wave period $T=8 \mathrm{sec}$, breaker wave angle $\alpha_{\mathrm{b}}=15 \mathrm{deg}$, and equilibrium-shaped profile for each grain size). This model predicts what most researchers feel is true, that suspended load transport is usually much more significant than bed-load transport on most fine-grain beaches most of the time. The discussion indicates that suspended load transport has a strong dependence on grain size. However, this would indicate that the CERC formula, which has no dependence on grain size, or the Kamphuis formula, which has only a weak dependence, should not have much predictive skill. This contradiction has been termed "the CERC formula paradox" by Nielsen $(1988,1992)$.

This paradox is at least partially resolved by noting that grain size is related to beach slope, as seen in the equilibrium beach profile concept (Dean 1977, 1991), and LST also is a function of beach slope, $m$, and the surf similarity parameter, $\xi$ :

$$
\xi=\frac{m}{\sqrt{H / L}}
$$

Larger grain sizes (shown previously to reduce the transport rate) are associated with beach profiles having steeper slopes, but steeper slopes are associated with greater transport rates. David Altman and Robert Dean have looked at the LST rate associated with beach fills and found greater transport on initial steep beach-fill profiles than on later, less steep profiles. (Personal Communication, 20 June 2005, Robert Dean, Professor, University of Florida). The surf similarity parameter has been related to breaker type (Battjes 1974), with milder slopes producing spilling breakers and steeper slopes producing plunging breakers. Nielsen (1991) commented that the type of breaking influences the surf zone turbulence levels, with mild slope spilling breakers producing less near-bed turbulence, and thus decreasing the suspended transport. The beach slope term is explicitly included in the Kamphuis model, with the effects on transport discussed previously. Several other researchers 


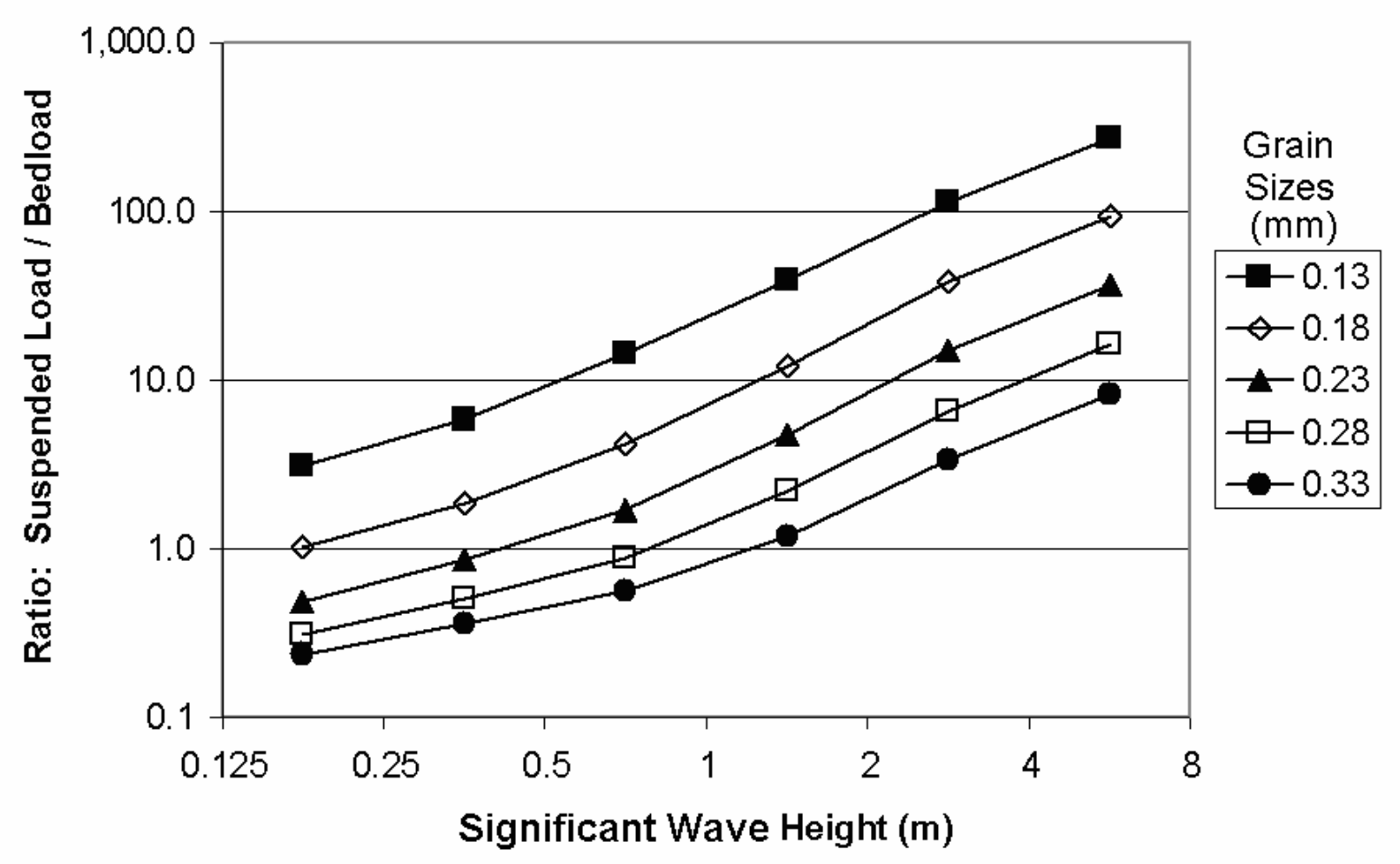

Figure 6. Ratio of suspended load to bed-load LST rate as predicted by Madsen and Tajima model

(Kamphuis and Readshaw 1970; Kamphuis and Sayao 1982; Ozhan 1982) have discussed relationships between the LST rate and the surf similarity parameter. This relationship is further explored by Smith et al. (2004).

The implication is that the beach slope, which is partially a function of grain size, should tend to counteract the decreased LST rate associated with the increased grain size effects discussed above. However, it is clear from the trend shown in Figure 3 that the dominant effect of increased grain size is to decrease the LST rate.

SUMMARY AND CONCLUSIONS: What is classically considered the bed-load transport regime is actually composed of two regimes, an Initial Motion (IM) bed-load regime, and a sheetflow bedload regime.

For coarse cobble and shingle beaches, where the top layer of the bed is not fully mobilized by wave action, the dominant regime is the IM bed-load regime. Though not well studied, the transport rate is inversely related to grain size, with $n$, the grain size exponent in Equation 7, of the order of -0.5 to -2 .

In the sheetflow bed-load regime, transport is largely independent of grain size.

In the suspended load regime, transport is strongly inversely related to grain size with $n$ being on the order of -3 (without considering the effects of beach slope). 
In the ripple regime, transport is expected to show the same grain size dependence as in the suspended load regime. In the absence of evidence to the contrary, in the swash regime, the dependence of the longshore transport on grain size is expected to be similar to that in bed-load or suspended load, depending upon which is dominant.

A relationship, Equation 23, between the grain size and the $K$ coefficient in the CERC formula is presented. However, there is substantial scatter in the data and the reader is cautioned to calibrate the value of $K$ using measured transport rates if the CERC formula is to be employed.

A series of LST rate models is presented and their predictions for the variation of transport with grain size are presented in Table 2 .

The assumption that the dominant mode of transport on most beaches is in the suspended load regime leads to a paradox. In general, LST rate data do not show the strong inverse dependence on grain size that would be expected in sediment suspension. This paradox is at least partially resolved by noting that there is a relationship between grain size and beach slope, and that variations in beach slope can also modify the transport rate.

In general, an increase in the median grain size will decrease LST rates in the surf zone. If a simple exponential relationship between transport rate and grain size $(D)$ is needed (Equation 7: LST rate $\propto$ $D^{n}$ ), the most appropriate value for the exponent $n$ should be of the order of -1 , as seen from Equation 23. However, this technical note argues that this is clearly a simplistic view of surf zone sediment dynamics. A more realistic (though still highly simplified) approach would be that, for fine grain sediments $\left(D_{50}\right.$ on the order of 0.15 to $0.30 \mathrm{~mm}$ ), suspended load transport should dominate and $n$ should be somewhere within the range of -0.5 to -3.0 . For coarse sands ( $D_{50}$ around $1.0 \mathrm{~mm}$ ), sheetflow bed-load transport should dominate (Figure 6) and the transport rate should be nearly independent of grain size $(n=0)$. For large gravel and shingle $\left(D_{50}>20 \mathrm{~mm}\right)$, the dominant transport should be in the IM bed-load regime, with $n$ within the range of -0.5 to -2.0 . To state it another way, the exponent $n$ in Equation 7 is itself a function of grain size.

ADDITIONAL INFORMATION: Questions about this CHETN can be addressed to Dr. David B. King, Jr. (Voice: 601-634-2087), (Fax: 601-634-4314), (e-mail: David.B.King@erdc.usace .army.mil), U.S. Army Engineer Research and Development Center, Coastal and Hydraulics Laboratory, HF-CI, 3909 Halls Ferry Road, Vicksburg, MS 39180-6199. The contributions of Ms. Julie Rosati, Dr. Bradley Johnson, and Mr. Ernest Smith, are gratefully acknowledged.

\section{REFERENCES}

Abou-Seida, M. M. (1965). "Bed load function due to wave action," Hydraulics Engineering Lab Report 2-11, University of California, Berkeley, $78 \mathrm{pp}$.

Ahrens, J. P. (2000). “A fall-velocity equation,” Journal of Waterway, Port, Coastal, and Ocean Engineering 126(2), 99-102, American Society of Civil Engineers.

Bagnold, R. A. (1940). "Beach formation by waves; Some model-experiments in a wave tank," Journal of the Institution of Civil Engineers, Paper Number 5237, 27-52. 


\section{ERDC/CHL CHETN-II-48}

\section{November 2005}

Bagnold, R. A. (1941). The Physics of Blown Sand and Desert Dunes, Methuen, London, 265 pp.

. (1946). "Motion of waves in shallow water, interaction between waves and sand bottoms," Proceedings Royal Society of London, Series A, 187, 1-18.

. (1954) "Experiments on a gravity-free dispersion of large solid spheres in a Newtonian fluid under shear," Proc Royal Society of London, Series A, 225, 49-63.

. (1956). "The flow of cohesionless grains in fluids," Proc Royal Society of London, Series A, 249, 239-297.

(1963). "Mechanics of marine sedimentation," The sea, Vol 3, 507-528, Wiley Interscience, New York.

. (1966). "An approach to the sediment transport problem from general physics," Geological Survey Professional Paper 422-I, U.S. Dept. of Interior.

Bailard, J. A. (1981). "An energetics total load sediment transport model for a plane sloping beach," Journal of Geophsical Research 86(C11), 10938-10954.

. (1984). "A simplified model for longshore sediment transport," Proceedings of the $19^{\text {th }}$ International Conference on Coastal Engineering, 1454-1470, ASCE.

Battjes, J. A. (1974). “Surf similarity," Proc. $14^{\text {th }}$ International Coastal Engineering Conference, Copenhagen, 466-480, ASCE.

Brampton, A. H., and Motyka, J. K. (1984). "Modelling the plan shape of shingle beaches," POLYMODEL 7 conference, Sunderland Polytechnic, UK.

Bodge, K. R., and Dean, R. G. (1987). "Short-term impoundment of longshore transport," Proceedings of Coastal Sediments '87, New York, 468-483, ASCE.

Bodge, K. R., and Kraus, N. C. (1991). "Critical examination of longshore transport rate magnitude," Proceedings of Coastal Sediments '91, Seattle, 139-155, ASCE.

Bruno, R. O., Dean, R. G., and Gable, C. G. (1980). "Littoral transport evaluations at a detached breakwater," Proceedings, $17^{\text {th }}$ Coastal Engineering Conference, 1453-1475, ASCE.

Chadwick, A. J. (1989). "Field measurements and numerical model verification of coastal shingle transport," Advances in water modeling and measurement. M. H. Palmer, ed., British Hydromechanics Research Association, Cranfield, 387-402.

Coastal Engineering Manual. (2002). Engineer Manual 1110-2-1100, U.S. Army Corps of Engineers, Washington, DC. (in 6 volumes). Available on-line at: http://www.usace.army.mil/inet/usace-docs/eng-manuals/cecw.htm

Damgaard, J. S., and Soulsby, R. L. (1996). Longshore Bedload Transport. Proceedings: $25^{\text {th }}$ International Conference on Coastal Engineering, ASCE, New York, (3), 3614-3627.

Dean, R. G. (1977). "Equilibrium beach profiles: U.S. Atlantic and Gulf coasts.” Dept of Civil Engineering, Ocean Engineering Rept No.12, University of Delaware.

(1978). "Review of sediment transport relationship and the data base," Proceedings, Workshop on Coastal Sediment Transport. University of Delaware, Sea Grant Program, 25-39.

. (1989). Measuring longshore transport with traps," Nearshore Sediment Transport. R. J. Seymour, ed., Plenum Press, New York. 313-336.

. (1991). "Equilibrium beach profiles: Principles and applications," J Coastal Research 7(1), 53-84. 
Dean, R. G., and Dalrymple, R. A. (2002). Coastal processes with engineering applications. Cambridge University Press, United Kingdom, 475 pp.

Dean, R. G., Berek, E. P., Gable, C. G., and Seymour, R. J. (1982). "Longshore transport determined by an efficient trap," Proceedings, $18^{\text {th }}$ International Conference on Coastal Engineering. Cape Town, 954-968, ASCE.

del Valle, R., Medina, R., and Losada, M. A. (1993). "Dependence of coefficient $K$ on grain size," Technical Note No. 3062, Journal of Waterways, Port, Coastal, and Ocean Engineering 119(5), 568-574.

Dohmen-Janssen, C. M. (1999). Grain-size influence on sediment transport in oscillatory sheet flow: Phase lags and model-bed effects. PhD Thesis, Delft University of Technology. Also, Rept 99-4, Communications on Hydraulic and Geotechnical Engineering, Delft University of Technology. 246 pp.

Elfrink, B. (1997). Longshore sediment transport in the swash zone. PhD Thesis. Series papers No. 63, Institute of Hydrodynamics and Hydraulic Engineering (ISVA) Technical University of Denmark ISSN 0107-1092, 153 pp.

Elfrink, B., and Baldock, T. (2002). "Hydrodynamics and sediment transport in the swash zone: A review and perspectives," Coastal Engineering 45, 149-167.

Fowler, J. E., Rosati, J. D., Hamilton, D. G., and Smith, J. M. (1995). "Development of a large-scale laboratory facility for longshore sediment transport research," The CERCular, CERC-95-2, U.S. Army Engineer Waterways Experiment Station, Vicksburg, MS.

Galvin, C. J. (1968). "Breaker type classifications of three laboratory beaches," Journal of Geophysical Research 73, 3651-3659.

Galvin, C., and Schweppe, C. R. (1980). "The SPM energy flux method for predicting longshore transport rate," Technical Paper 80-4, U.S. Army Corps of Engineers, Coastal Engineering Research Center, Fort Belvoir, VA. $34 \mathrm{pp}$.

Greer, M. N., and Madsen, O. S. (1978). "Longshore sediment transport data: A review," Proc, $16^{\text {th }}$ Coastal Engineering Conference, Hamburg, 93(2), 1563-1576.

Guza, R. T., and Thornton, E. B. (1982). "Swash oscillations on a natural beach," Journal of Geophysical Research 87(C1), 483-491.

Hallermeier, R. J. (1981). “Terminal settling velocity of commonly occurring sand grains," Sedimentology (28).

Hamilton, D. G., Ebersole, B. A., Smith, E. R., and Wang, P. (2001). "Development of a large-scale laboratory facility for sediment transport research," Technical Report ERDC/CHL TR-01-22, U.S. Army Engineer Research and Development Center, Vicksburg, MS.

Horn, D. P., and Mason, T. (1994). "Swash zone sediment transport modes," Marine Geology 120, 309-325.

Inman, D. L., and Bagnold, R. A. (1963). “Littoral processes,” The sea Vol 3, Wiley-Interscience, New York.

Jonsson, I. G. (1966). "Wave boundary layers and friction factors," Proc 10th Coastal Engineering Conf, Tokyo, 127-148, ASCE.

Kalkanis, G. (1964). “Transport of bed material due to wave action," CERC TM-2, U.S. Army Engineer Waterways Experiment Station, Vicksburg, MS.

Kamphuis, J. W. (1975). "Friction factor under oscillatory waves," Journal of Waterway, Harbors and Coastal Eng Div, 101:WW2, 135-144, ASCE. 


\section{ERDC/CHL CHETN-II-48}

\section{November 2005}

Kamphuis, J. W. (1991). "Alongshore sediment transport rate," Journal of Waterway, Port, Coastal and Ocean Engineering 117(6), 624-641, ASCE.

. (2002). "Alongshore transport of sand," Proceedings of the $28^{\text {th }}$ International Conference on Coastal Engineering, 2478-2490, ASCE.

Kamphuis, J. W., and Readshaw, J. S. (1978). "A model study of alongshore sediment transport," Proceedings $21^{\text {st }}$ International Conference on Coastal Engineering, Malaga, 1253-1264, ASCE.

Kamphuis, J. W., and Sayao, O. F. S. J. (1982). "Model tests on littoral sand transport rate," Proceedings $18^{\text {th }}$ International Conference on Coastal Engineering, Cape Town, 1305-1325, ASCE.

Kamphuis, J. W., Davies, M. H., Narim, R. B., and Sayao, O. J. (1986). "Calculation of littoral sand transport rate," Coastal Engineering 10, 1-21.

Karambas, T. V., and Karathanassi, E. K. (2004). "Longshore sediment transport by nonlinear waves and currents," Journal of Waterway, Port, Coastal and Ocean Engineering, 130(6), 277-286, ASCE.

King, D. B. (1991). Studies in oscillatory flow bedload sediment transport. PhD Thesis, University of California, San Diego (Scripps Institution of Oceanography), 183 pp.

King, D. B., and Seymour, R. J. (1989). "State of the art in oscillatory flow sediment transport models," Nearshore Sediment Transport. R. J. Seymour, ed., Plenum Press, New York.

Komar, P. D. (1988). "Environmental controls on littoral sand transport," Proceedings of the $21^{\text {st }}$ International Conference on Coastal Engineering, 1238-1252, ASCE.

Komar, P. D., and Inman, D. L. (1970). "Longshore sand transport on beaches," Journal of Geophysical Research 75(30), 5514-5527.

Kraus, N. C., Isobe, M., Igarashi, H., Sasaki, T. O., and Horikawa, K. (1982). "Field experiments on longshore transport in the surf zone," Proceedings of the 18th International Conference on Coastal Engineering, New York, 969-988, ASCE.

Kumada, T., Kobayashi, A., Uda, T., and Serizawa, M. (2003). "Development of predictive model of shoreline and grain size changes," Proceedings, Coastal Sediments '03, ASCE.

Leidersdorf, C. B., Gadd, P. E., and McDougal, W. G. (1988). "Arctic slope protection methods," Proceedings, $21^{\text {st }}$ International Conference on Coastal Engineering, Malaga, 1687-1701, ASCE.

Madsen, O. S., and Grant, W. D. (1976). Sediment Transport in the Coastal Environment, MIT Per. No. 209, 120 pp.

Manohar, M. (1955). Mechanics of bottom sediment motion due to wave action, Beach Erosion Board TM-75, U.S. Army Corps of Engineers.

Miller, H. C. (1998). "Comparison of storm longshore transport rates to predictions," Proceedings of the 26th Conference on Coastal Engineering, 2954-2967, ASCE.

Morfett, J. C. (1988). "Modelling shingle beach evolution," IAHR Symposium: Mathematical Modelling of Sediment Transport in the Coastal Zone, Copenhagen, 148-155.

Nicholls, R. J., and Webber, N. B. (1987). “Aluminum pebble tracer experiments on Hurst Castle Spit,” Proceedings, Coastal Sediments '87, New Orleans, 1563-1577, ASCE.

Nicholls, R. J., and Wright, P. (1991). "Longshore transport of pebbles, experimental estimates of K," Proceedings, Coastal Sediments '91, Seattle, 920-933, ASCE. 
Nielsen, P. (1979). “Some basic concepts of wave sediment transport," ISVA Series Paper 20, Technical University of Denmark.

. (1988). "Three simple models of wave sediment transport," Coastal Engineering 12, 43-62.

. (1991). "Combined convection and diffusion: A new framework for suspended sediment modeling," Proceedings, Coastal Sediments '91, Seattle, 418-431, ASCE.

(1992). "Coastal bottom boundary layers and sediment transport," Advances in Ocean Engineering 4. World Scientific, Singapore, 324 pp. (45), 53-60.

(2002). "Shear stress and sediment transport calculations for swash zone modeling," Coastal Engineering

O'Donoghue, T., and Wright, S. (2004). "Flow tunnel measurements of velocities and sand flux in oscillatory sheet flow for well-sorted and graded sands," Coastal Engineering 51(11-12), 1163-1184.

Ozhan, E. (1982). "Laboratory study of breaker type effect of groins on the rate of littoral transport," Proc, Euromech 156: Mechanics of Sediment Transport, B. M. Sumer and A. Muler, ed.

Ribberink, J. S., and Al-Salem, A. A. (1994). "Sediment transport in oscillatory boundary layers in cases of rippled beds and sheet flow," Journal of Geophysical Research 99, NO. C6, 12,707-12,727.

Sawamoto, M., and Yamashita, T. (1986). "Sediment transport rate due to wave action," Journal of Hydroscience and Hydraulic Engineering 4(1), 1-15.

. (1987). "Sediment transport in sheet flow regime," Proc, Coastal Sediments '87, 415-423, ASCE.

Schoonees, J. S., and Theron, A. K. (1993). "Review of the field database for longshore sediment transport," Coastal Engineering 19, 1-25.

. (1994). "Accuracy and applicability of the SPM longshore transport formula," Proceedings of the $24^{\text {th }}$ Coastal Engineering Conference, 2595-2609, ASCE.

Shore protection manual. (1973). U.S. Army Engineer Waterways Experiment Station, U.S. Government Printing Office, Washington, DC.

(1984). U.S. Army Engineer Waterways Experiment Station, U.S. Government Printing Office, Washington, DC.

Sleath, J. F. A. (1978). "Measurements of bed load in oscillatory flow," Journal of Waterway, Port, Coastal, and Ocean Engineering 104(WW4), 291-307, ASCE.

(1984). Sea bed mechanics, John Wiley \& Sons, NY, 335 pp.

Smith, E. R., Ebersole, B. A., and Wang, P. (2004). "Dependence of total longshore sediment transport rates on incident wave parameters and breaker type," Coastal and Hydraulics Engineering Technical Note, CHETN IV-62, U.S. Army Engineer Research and Development Center, Vicksburg, MS.

Soulsby, R. (1997). The dynamics of marine sands. Thomas Telford Publications, 249 pp.

Swart, D. H. (1974). Offshore sediment transport and equilibrium beach profiles. Delft Hydr Lab Publication No 131. ASCE.

(1976). "Predictive equations regarding coastal transports," Proc 15th Coastal Eng Conf, 1113-1132, 
Tajima, Y. (2004). Waves, currents, and sediment transport in the surf zone along long, straight beaches. PhD Thesis, Massachusetts Institute of Technology, 313 pp.

U.S. Army Engineer Waterways Experiment Station. (1985). "Sediment size and fall velocity effects on longshore sediment transport," Coastal Engineering Technical Note, CETN-II-11, Coastal Engineering Research Center, Vicksburg, MS, Available on-line at: http://chl.erdc.usace.army.mil/library/publications/chetn/pdf/cetn-ii-11.pdf

van Hijum, E., and Pilarczyk, K. W. (1982). Equilibrium profile and longshore transport of coarse material under regular and irregular wave attack. Publication No. 174, Delft Hydraulics Laboratory. Netherlands.

Van Wellen, E., Baldock, T., Chadwick, A., and Simmonds, D. (2000). "STRAND - A model for longshore sediment transport in the swash zone," Proceedings of the $27^{\text {th }}$ Conference on Coastal Engineering, 3139-3150, ASCE.

Van Wellen, E., Chadwick, A. J., and Mason, T. (2000). "A review and assessment of longshore sediment transport equations for coarse-grained beaches," Coastal Engineering 40, 243-275.

Van Wellen, E., Chadwick, A. J., Lee, M., Baily, B., and Morfett, J. (1998). "Evaluation of longshore sediment transport models on coarse grained beaches using field data: A preliminary investigation." Proceedings of the $26^{\text {th }}$ Conference on Coastal Engineering, 2640-2653, ASCE.

Vitale, P. (1980). “A guide for estimating longshore transport rate using four SPM methods.” Technical Aid No. 80-6, U.S Army Corps of Engineers, Coastal Engineering Research Center, Fort Belvoir, VA.

Walton, T., and Chiu, T. (1979). "A review of analytical techniques to solve the sand transport equation and some simplified solutions," Proceedings of Coastal Structures '79, 809-837, ASCE.

Wang, P., and Kraus, N. C. (1999). "Longshore sediment transport rate measured by short-term impoundment," Journal of Waterway, Port, Coastal, and Ocean Engineering 125, 118-126, ASCE.

Wang, P., Kraus, N. C., and Davis, R. A. (1998). "Total rate of longshore sediment transport in the surf zone: field measurements and empirical predictions." Journal of Coastal Research 14(1), 269-283.

NOTE: The contents of this technical note are not to be used for advertising, publication, or promotional purposes. Citation of trade names does not constitute an official endorsement or approval of the use of such products. 